Laureles (Teatro Rambla, La Plata, 1983). Texto, proceso creativo e investigación territorializada

Ricardo Dubatti

Boletín de Arte (N. $\left.{ }^{\circ} 20\right)$, e022, septiembre 2020, ISSN 2314-2502

https://doi.org/10.24215/23142502e022

http://papelcosido.fba.unlp.edu.ar/ojs/index.php/boa

Facultad de Artes. Universidad Nacional de La Plata

La Plata. Buenos Aires. Argentina

\title{
LAURELES (TEATRO RAMBLA, LA PLATA, 1983)
}

\section{TEXTO, PROCESO CREATIVO E INVESTIGACIÓN TERRITORIALIZADA}

\section{LAURELES (TEATRO RAMBLA, LA PLATA, 1983)}

\author{
TEXT, CREATIVE PROCESS AND TERRITORIALIZED INVESTIGATION
}

Ricardo Dubatti / ricardo.dubatti@gmail.com

Consejo Nacional de Investigaciones Científicas y Técnicas (CONICET) / Instituto de Artes del Espectáculo. Universidad de Buenos Aires. Argentina

Recibido: $17 / 2 / 2020$

Aceptado: 8/7/2020

\section{RESUMEN}

En 1983, a poco más de un año de finalizada la Guerra de Malvinas, y aún no concluido el gobierno de facto del Proceso de Reorganización Nacional (1976-1983), el grupo independiente Teatro Rambla (La Plata, Provincia de Buenos Aires) estrenó Laureles, pieza de un valor excepcional para la historia de las representaciones del conflicto bélico en el teatro argentino. Se trata de una de las primeras representaciones explícitas de la Guerra de Malvinas en la escena nacional, al mismo tiempo, fundacional y anticipatoria. En el presente artículo focalizaremos en la condición posescénica y heteroestructurada de su texto dramático, resultado de un complejo proceso de composición del antes, durante y después de los ensayos, así como de una investigación territorializada en La Plata sobre la Guerra de Malvinas.

\section{PALABRAS CLAVE}

Cartografía teatral; Guerra de Malvinas; poética genética; representación; dramaturgia

\section{ABSTRACT}

In 1983, more than a year after the end of the Malvinas War, and but still in the context of the de facto government of the National Reorganization Process (1976-1983), the independent group Teatro Rambla (La Plata, Province of Buenos Aires) premiered Laureles, a piece of exceptional value for the history of representations of the war in the Argentine theater. It is one of the first explicit representations of the Malvinas War on the national scene, at the same time foundational and anticipatory. In this article we will focus on the post-scenic and heterostructured condition of this dramatic text, the result of a complex composition process before, during and after the rehearsals, as well as a territorialized investigation in La Plata on the Malvinas War.

\section{KEYWORDS}

Theatrical cartography; Malvinas War; genetic poetics; representation; dramaturgy 
En 1983, a poco más de un año de finalizada la Guerra de Malvinas y aún no concluido el gobierno de facto del Proceso de Reorganización Nacional (1976-1983), el grupo independiente Teatro Rambla (La Plata, provincia de Buenos Aires) estrenó Laureles, notable texto dramático de Mónica Greco y José Luis de las Heras. ${ }^{1}$ Su intención era resistir a la política de desmalvinización ${ }^{2}$ (iniciada por el Ejército apenas concluida la guerra) y llevar a escena el horror de la violencia en los años de la dictadura. Pieza clave en nuestra investigación ${ }^{3}$ (cuyo corpus reúne más de cien textos dramáticos y espectáculos, compuestos entre 1982 y 2020), ${ }^{4}$ Laureles posee un valor excepcional: constituye una de las primeras representaciones (Chartier, 1992, 2007) explícitas de la Guerra de Malvinas en el teatro argentino, y lo hace a través de una poética de gran complejidad y una potente visión crítica y política.

La proximidad temporal de Laureles a los acontecimientos históricos podría presuponer limitaciones en el acceso a la información y a las fuentes documentales. También, una mayor dificultad para elaborar una lectura distanciada sobre la historia reciente. Sin embargo, Laureles es un aporte insoslayable porque funda varios de los topics teatrales (Eco, [1979] 1993, pp. 125-137) que serán luego retomados por otras dramaturgias posteriores. ${ }^{5}$ Fundacional y anticipatoria, Laureles ocupa un lugar central en la historia teatral de las representaciones de la Guerra de Malvinas. Hay que destacar, además, su relevancia cartográfica: ${ }^{6}$ La Plata, como veremos, fue una de las ciudades donde la población civil se presentó más organizada durante el conflicto y en la posguerra.

El texto dramático de Laureles se mantuvo inédito hasta hoy, ${ }^{7}$ en versión mecanografiada de 1983, con intervenciones manuscritas. En el presente artículo, por razones de extensión, veremos uno de los aspectos más relevantes de dicho texto: su condición posescénica y heteroestructurada, ${ }^{8}$ resultado de un complejo proceso de composición antes, durante y después de los ensayos, así como de una investigación territorializada en La Plata sobre la Guerra de Malvinas. Previamente ubicaremos la escritura de Laureles en algunas coordenadas de la historia de Teatro Rambla.

1 Agradecemos al doctor Gustavo Radice, quien nos asesoró en nuestra investigación sobre las representaciones de la Guerra de Malvinas en el teatro platense y nos facilitó el texto dramático de Laureles y otros materiales de su archivo, así como el contacto con los autores.

2 El término desmalvinización, creado por Alain Rouquié (en Soriano, 1983), se refiere a las diversas omisiones (estatales, civiles, militares, económicas, etcétera) que buscan invisibilizar las problemáticas (positivas o negativas) de la Guerra de Malvinas y, por extensión, de la causa Malvinas. Comienza cuando, tras la rendición, varios soldados son obligados por el Ejército a firmar un documento en el que se comprometían a no hablar de la guerra, especialmente con la prensa (Lorenz, 2007).

3 Beca doctoral del CONICET: Representaciones de la Guerra de Malvinas (1982) y sus consecuencias socioculturales en el teatro argentino (1982-2007): poéticas dramáticas, historia y memoria, bajo la dirección de Hugo Mancuso y la codirección de Mauricio Tossi.

4 Véase el ítem "Corpus» en nuestro «Prólogo. La guerra en el teatro: representar la Guerra de Malvinas en la escena" (Dubatti, 2020a). Laureles se subclasifica en el Grupo I, correspondiente a obras argentinas (escritas, estrenadas en la Argentina) o de creadores argentinos (que escriben, estrenan fuera del país) que desarrollan explícitamente la temática de la Guerra de Malvinas (sean los antecedentes de la guerra, los hechos bélicos y/o la posguerra) en formato total o fragmentario, y/o que explicitan su representación de la guerra a través de metatextos (Dubatti, 2019, 2020a).

5 Es la tercera obra escrita y la segunda estrenada sobre el tema, inmediatamente después de El Señor Brecht en el Salón Dorado, de Abelardo Castillo (estrenada en 1982 y reestrenada en nueva versión en Teatro Abierto 1983), y El fusil de madera, de Duilio Lanzoni (escrita en 1983, pero recién estrenada en 1985).

6 Para los conceptos de cartografía teatral y territorialidad, ver Teatro y territorialidad. Perspectivas de Filosofía del Teatro y Teatro Comparado (2020), de Jorge Dubatti.

7 El texto dramático se encuentra actualmente en prensa (Dubatti, 2020b), con introducción de Gustavo Radice. 8 Para la clasificación de los textos dramáticos, desde una poética genética, según su relación compositiva con la escena (preescénicos de primer y segundo grado, escénicos, posescénicos), y sobre su carácter homoestructurado/heteroestructurado, seguimos "Dramaturgias escénicas, escrituras y reescrituras teatrales: reflexiones teóricas hacia Medea (2009), dirección de Pompeyo Audivert» (2019), de Jorge Dubatti. 


\section{DRAMATURGIA PROPIA, SEUDÓNIMOS E INCIDENCIA SOCIAL}

Laureles se estrenó el 15 de octubre de 1983 en la sala de ensayo de Teatro Rambla, ubicada en calle 2, entre 48 y $49 . .^{9}$ Los dramaturgos firmaron el texto con seudónimos: León Forner (Greco) y José Burón (de las Heras). ¿Por qué? El contexto político y social del estreno era complejo: si bien las elecciones estaban cerca (se realizaron el 30 de octubre de 1983) y ya se producía una transición a la democracia, la presencia de las fuerzas militares de facto aún constituía una potencial amenaza que motivaba cautela. Incluso, luego del 10 de diciembre de 1983 (cuando asumió la presidencia Raúl Alfonsín e, institucionalmente, comenzaba una nueva etapa), se inició en la Argentina un período (correspondiente a 1983-1989) calificado de democracia condicionada, enmarcado en una unidad mayor de postdictadura, en el que la perduración de estructuras de subjetividad dictatorial todavía era muy fuerte y desestabilizaba permanentemente las dinámicas del flamante orden constitucional recuperado (Dubatti, 2015). En su introducción a la edición del texto de Laureles, Gustavo Radice (2020) observa, por otro lado, que en ese contexto el seudónimo masculino permitía a Greco trabajar con mayor libertad, dando una mejor circulación a sus materiales. Ya en postdictadura, tanto Greco como de las Heras mantendrán los seudónimos respectivos para firmar otros textos dramáticos.

Teatro Rambla cuenta con más de cuarenta años de trayectoria en el circuito de producción independiente platense y sigue produciendo en la actualidad. Radice (2020) afirma que el Taller de Teatro Rambla se fundó hacia comienzos de la década de 1970. Tras trabajar con autores diversos —entre los que se destacan Extraño juguete (1977), de Susana Torres Molina, y El Señor Galíndez (1973), de Eduardo Pavlovsky-, el grupo comenzó a producir dramaturgia propia. En 1979 Rambla pasó a la sala que ocupa hoy (calle 2, entre 48 y 49). Radice (2020) señala que "fue el primer grupo de teatro independiente platense en contar con sala propia» (s. p.). En otro artículo, Radice y Natalia Di Sarli (2009) observan:

La elección de sus textos — Susana Torres Molina, Eduardo Pavlovsky — marca las líneas de una de las micropoéticas que, sin ser partidistas, buscaron sus referentes dentro de los conflictos del campo de poder. En la constante preocupación por establecer un vínculo entre las prácticas sociales y el teatro, las producciones del Teatro Rambla intentaron instituir un teatro de corte político que ahondó en el conflicto del individuo y su relación con el campo de poder (s. p.).

Entre los modelos teatrales de Teatro Rambla figuran Antonin Artaud, Bertolt Brecht y Erwin Piscator. Radice y Di Sarli (2009) relacionan la macropoética del grupo con una matriz "realista-expresionista" (s. p.). En otro estudio, Radice y Di Sarli (2008) describen dos tendencias teatrales dominantes en el teatro independiente de La Plata entre 1983 y 1986. La primera proponía "establecer líneas de acción que tendían a la puesta en conciencia de lo sucedido en los años de la dictadura (Teatro Rambla, Devenir) a partir de un teatro de denuncia de corte más explícito en su referente" (p. 2). La segunda, en contraste, "tendió a la experimentación formal, sin descuidar lo ideológico, pero que en cuyo entramado estaba implícito lo sucedido durante la década pasada» (Radice \& Di Sarli, 2008, p. 2). A pesar de sus diferencias, "ambas vertientes apropian la incipiente libertad de expresión para potenciar los lenguajes teatrales desde la construcción de micropoéticas particulares» (Radice \& Di Sarli, 2008, p. 2). Esto implicó un giro ante la producción teatral platense de la década previa, tendiente a la homogeneidad debido a su trabajo sobre la metáfora con «referentes y procedimientos [que] se desarrollaron conjuntamente en pos de "decir lo que no se dice"»

9 Ficha artístico-técnica. Actores: Diego Ferrando, Marcelo Linares, Roberto Consolo, Gustavo Boggia, Adriana García, Marité Lucarena, Alejandra Rómoli, Mónica Zapatería, Sandra Argüero, Carolina Alberdi, Laura Cucchetti. Coreografía: Laura Cucchetti. Dirección: José Luis de las Heras. Vestuario: Chony de las Heras. Asistente de dirección, diseño de espacio: Carlos Zelubowski. lluminación, diseño sonoro: Benjamín Compson. Montaje sonoro: Poli. Fotografía, diseño gráfico: Ángel Radaelli. Asistencia técnica: Sandra Lentz. Música de Mahler, Fischer, Newman y «Renacer», de Diego Ferrando. 
(Radice \& Di Sarli, 2008, p. 2). La labor de Teatro Rambla inmediatamente posterior a Laureles atraviesa las diversas etapas de la postdictadura. Luego de 1986 se produce:

[...] retracción del teatro independiente hasta comenzada la década del 90 [...]. Durante 1986 y como consecuencia de la crisis económica, de la falta de promoción de los espectáculos, de la desaparición de salas teatrales y de la ausencia de una política cultural, el circuito de teatro independiente sufre una progresiva disolución y merma de público, quedando dicho circuito aislado a unos pocos grupos que cuentan con sala propia y amplia trayectoria (Radice \& Di Sarli, 2008, pp. 2-3).

Los años noventa marcan un proceso de paulatina estabilización del teatro independiente platense, en el que Teatro Rambla afirma su protagonismo.

\section{PROCESO CREATIVO DE COMPOSICIÓN DE LAURELES}

El texto dramático de Laureles se mantuvo inédito hasta hoy, en versión mecanografiada de 1983, con intervenciones manuscritas. El mismo no porta una división en estructura externa (actos, cuadros, escenas, etcétera), pero tampoco opera completamente como un continuum. En el original mecanografiado se observan saltos de página que evidencian una organización de la intriga en unidades internas. Cada unidad de intriga se inicia en un nuevo folio y los folios en que se cierra una unidad pueden quedar con buena parte de la página en blanco. Según esa peculiar distribución del texto por saltos de folio, Laureles se divide en dieciséis unidades. El inicio de cada unidad lleva una nota manuscrita en el margen superior derecho, que sugiere un nombre de referencia, y solo en algunos casos incluye el término escena: "Escena Presentación (comienzo)" (Greco \& de las Heras, 1983a, p. 1), "Primera carta» (p. 2), «Escena Soldado-Laurita $\left(1^{\circ}\right)$ " (p. 3), etcétera.

Tanto la división de las escenas en folios, como las anotaciones y las correcciones manuscritas, evidencian instancias de su poética genética: se trata de un texto posescénico que surge del progresivo proceso de trabajo escénico en los ensayos sobre primeros borradores preescénicos (aportados por Mónica Greco), así como de los ajustes y las revisiones anteriores y posteriores al estreno. En ese cruce de tiempos, el texto presenta algunos pasajes no totalmente unificados, situación que pone en primer plano el carácter heteroestructurado del texto, atravesado por matrices de literaturidad y teatralidad.

En un metatexto de 1983, previo al estreno de la pieza, Teatro Rambla reflexionó sobre la Guerra de Malvinas. De las Heras, director y coautor de Laureles, explicó en El Día (en Los "Laureles" que no pudimos conseguir, 1983) que el grupo concebía el arte escénico como hecho estético y como herramienta para incidir sobre la realidad social:

Podemos pecar de pretenciosos, pero si a partir de la obra se empieza a tomar conciencia de que los chicos [de la Guerra de Malvinas] están mal y que ya están acá, con ideas claras de lo que quieren y sin olvidar el horror de todo aquello, quizás podamos revertir esa falta de gratitud de la sociedad, que pese a los vivas del retorno ya se olvidó de ellos. [...]. Hacer un arte que no se agote en sí mismo o en un mero gusto estético, sino el arte transformador que busca el bien (p. 6).

Allí se objetivaba a su vez la compleja relación entre escena y memoria del pasado reciente. Observó de las Heras (en Los «Laureles» que no pudimos conseguir, 1983):

Aún resta mucho tiempo para que pueda realizarse un espectáculo teatral que compendie todo lo que fue aquello. [...]. Pero corríamos el riesgo de que la falta de una realización como la aquí planteada produjera un desgaste del tema. Que quedara definitivamente en el olvido (p. 6).

Luego el director remarcaba su deseo de producir "una segunda Laureles" (Los "Laureles" que no pudimos conseguir, 1983) para completar la información sobre los hechos 
históricos. De las Heras también afirmó que su interés estuvo puesto en "los dramas humanos", aquello sobre "lo que muy pocos inquieren" (Los "Laureles" que no pudimos conseguir, 1983, p. 6).

En una crítica sobre Laureles firmada por Eduardo Atencio, publicada el 19 de octubre de 1983 en El Día, se sugería el carácter polémico de la pieza debido a que «va lindando la senda del derrotismo", y se valoraba el uso de una labor escénica marcada por "un singular realismo" (s. p.). Un mes más tarde se publicó en el mismo medio un texto breve que anunciaba la continuidad de las funciones. Allí se afirma que el elenco se integraba por "participantes de distintas promociones de la institución» (Sigue "Laureles» en el Rambla, 1983, s. p.).

El programa de mano del espectáculo incluía paratextos: dos imágenes documentales vinculadas a la guerra, cada una acompañada por un epígrafe que describía su contenido. En el anverso, se presentaba una foto de dos combatientes argentinos comiendo en Puerto Argentino/Stanley, con la inscripción: «Puerto Islas Malvinas [sic], 14 de abril: dos soldados Argentinos [sic] almuerzan ayer en la zona portuaria de esta ciudad" (Greco \& de las Heras, 1983b). En el reverso, se exponía a soldados británicos frente a las tumbas del cementerio de Puerto Darwin. El epígrafe, en inglés, decía:

20/2/83: Darwin, Isla Soledad: Esta foto oficial, publicada el 20 de febrero, muestra tropas británicas del Primer Batallón del Regimiento Real de Hampshire el 19/2 marchando despacio hacia el nuevo cementerio militar cerca de Darwin, Isla Soledad, donde 221 soldados, marineros y correos argentinos muertos en el conflicto de Malvinas del año pasado han sido vueltos a enterrar con honores militares. Luego de las oraciones una salva fue disparada por encima de las tumbas y se interpretó el toque de retirada (Greco \& de las Heras, 1983b)..$^{10}$

En el citado metatexto, anterior al estreno de Laureles, se señalaba el trabajo territorial sobre la guerra llevado a cabo por el grupo:

Para La Plata, el hecho adquiere particular significación dentro del contexto de todo el país, porque precisamente muchos de los ex combatientes de Malvinas son hijos de nuestra ciudad, y algunos de ellos regaron generosamente con su sangre ese suelo insular tan caro al sentimiento nacional (Los "Laureles" que no pudimos conseguir, 1983, p. 6).

Con relación al trabajo y la conciencia territoriales, Teatro Rambla tomó contacto con el Centro de Ex Combatientes Islas Malvinas (CECIM) en La Plata, una de las organizaciones más visibles vinculadas a la guerra y la posguerra. Por otro lado, La Plata fue una de las ciudades donde la población civil se presentó más organizada durante el conflicto y en la posguerra. En el temprano libro El otro frente de la guerra. Los padres de las Malvinas (1982), de Dalmiro Bustos, se relatan los esfuerzos de los familiares para ayudar a los soldados y a sus parientes de la ciudad. La experiencia de los platenses también es testimoniada en Los chicos de la guerra. Hablan los soldados que estuvieron en Malvinas (1982), de Daniel Kon (anterior al libro de Bustos), en el que se basará libremente la película homónima, de Bebe Kamin (recién estrenada en 1984). Como León Forner (es decir, valiéndose de su seudónimo), Greco explicaba en la misma nota de El Día:

Nuestros primeros contactos fueron con los soldados ex combatientes del CECIM y allí fuimos a buscar esos elementos que no figuran en la crónica periodística. No queríamos estadísticas, sino sanciones, buscábamos los fantasmas de los soldados en la trinchera (Los «Laureles» que no pudimos conseguir, 1983, p. 6).

10 "2/20/83: Darwin, East Falklands: This official photo released 2/20 shows British troops of the 1st Battalion The Royal Hampshire Regiment slow marching into the new military cemetery 2/19 near Darwin, East Falkland, where 221 Argentine soldiers, sailors and mailman killed in the last year's Falkland conflict have been reburied with military honors. After prayers a volley was fired over the graves and the Last Post builded" (Greco \& de las Heras, 1983b). La traducción es del autor del artículo. 
En una entrevista con Mónica Greco, la dramaturga se refiere a la recolección de testimonios y de información para la escritura de la obra:

Recuerdo que hablamos con ex combatientes, sobre todo con uno de ellos, ex alumno del Colegio Nacional, egresado de la misma camada que el actor que interpretaba al soldado, Diego Ferrando. Inclusive muchas de esas charlas fueron grabadas. También fue de mucha ayuda un librito con todos los comunicados oficiales del ejército británico y el argentino, y un grupo de cartas originales de soldados a sus padres, cartas que nos acercaron algunas familias. Recuerdo haber trabajado con un mapa grande de las islas donde la gente del CECIM me había marcado los lugares de combate del Regimiento 7 de La Plata. Esas tres cosas estaban permanentemente al lado de la vieja Olivetti, y los cigarrillos, claro (Greco en Dubatti, 16 de marzo de 2020).

En relación con la consulta de los libros de Bustos (1982) y de Kon (1982), afirma en la misma entrevista:

El libro de Bustos lo leí, lo que no sé si antes o después de terminar Laureles, ya que yo estuve trabajando desde mayo o junio de 1983. El señor Bustos vivía muy cerca de mi casa, y le llevé invitaciones para ver la obra, no vino, pero me mando una notita diciendo que estaba en Brasil y que muchas gracias. Lo que es seguro que Los chicos de la guerra lo leí ya estrenada la obra. La leí después de ver la película, y me quedé bastante asombrada de las similitudes con Laureles, sobre todo con el uso del flash-back (Greco en Dubatti, 16 de marzo de 2020).

En otra entrevista que realizamos a Mónica Greco, comenta sobre el proceso creativo:

Laureles fue creada por los dos [junto a José Luis de las Heras]. Si bien los textos fueron míos, es José quien me trae la idea del tema. Yo protesté, porque siempre protesto... Y además, porque pensaba que llevar a escena una situación bélica, sobre todo en una producción independiente, se iba a ver pobre y falsa. A menos que... Y en ese "a menos que» estuvo la búsqueda de la cosa no realista un tanto onírica (Greco en Dubatti, 5 de enero de 2020).

Greco explicita la existencia de materiales preescénicos sometidos en los ensayos a reelaboración de investigación escénica. Agrega:

Yo escribía las escenas, las mandaba de a poco y con ese material se ensayaba. Cuando hice el final, se armó como un rompecabezas y se reescribió para transformarlo en un libreto, con el que pudieran trabajar tanto los actores como el iluminador y el sonidista, ya que la pieza tenía muchísimas grabaciones de la época, discursos, comunicados, etc. que servían de nexos entre escenas. Ese armado también lo realizo José [de las Heras] y en la puesta hubo más cambios (Greco en Dubatti, 5 de enero de 2020).

En la entrevista del 16 de marzo de 2020, Greco recuerda:

Siempre me lamentaré que no haya podido incluir tantas cosas muy ricas que me contaron, es que Laureles quedó muy larga... Uno de los chicos [ex combatientes], que amaba a Pappo, hizo un relato maravilloso de cómo se robó una oveja y la carneó ahí nomás en medio del campo helado con la bayoneta y se llevó los pedazos al pozo en la cima del Monte Longdon donde esperaban los compañeros (Greco en Dubatti, 16 de marzo de 2020).

\section{CONCLUSIÓN}

Como señalamos, luego del proceso de ensayos, Greco y de las Heras redactan un texto posescénico definitivo, que publicarán en coedición el Instituto Nacional del Teatro y el Centro Cultural de la Cooperación (Dubatti, 2020b). En el entramado final de dicho texto, heteroestructurado a la par por matrices de literaturidad y teatralidad, está presente el aporte colectivo de todo el equipo creativo involucrado en los ensayos, así como la reelaboración 
escénica de documentación y de testimonios. Como sucede con los textos posescénicos, el espesor escénico de los ensayos (improvisación, investigación, reescritura) forma parte del campo referencial a la vez interno y externo del texto (Harshaw, 1984). ¿Por qué es relevante atribuir al texto dramático de Laureles la condición de posescénico? Porque la inclusión del proceso grupal otorga al texto una dimensión política, social y cultural que multiplica la incidencia territorial de Teatro Rambla.

\section{REFERENCIAS}

Atencio, E. (19 de octubre de 1983). "Laureles", y una prolongada y cruel agonía en las trincheras. El Día, s. p.

Bustos, D. (1982). El otro frente de la guerra. Los padres de las Malvinas. Ciudad Autónoma de Buenos Aires, Argentina: Ramos Americana.

Chartier, R. (1992). El mundo como representación. Estudios sobre historia cultural. Barcelona, España: Gedisa.

Chartier, R. (2007). La historia o la lectura del tiempo. Barcelona, España: Gedisa.

Dubatti, J. (2015). La escena teatral argentina en el siglo XXI. Permanencia, transformaciones, intensificaciones, aperturas. En L. A. Quevedo (Comp.), La cultura argentina hoy. Tendencias! (pp. 151-196). Ciudad Autónoma de Buenos Aires, Argentina: Siglo Veintiuno, Fundación OSDE.

Dubatti, J. (2019). Dramaturgias escénicas, escrituras y reescrituras teatrales: reflexiones teóricas hacia Medea (2009), dirección de Pompeyo Audivert. AURA. Revista de Historia y Teoría del Arte, (9), 19-37. Recuperado de http://www.ojs.arte.unicen.edu.ar/index.php/ aura/article/view/662/546

Dubatti, J. (2020). Teatro y territorialidad. Perspectivas de Filosofía del Teatro y Teatro Comparado. Barcelona, España: Gedisa.

Dubatti, R. (2019). Prólogo. Teatro de la guerra: corpus de representaciones de la Guerra de Malvinas en textos dramáticos y espectáculos. En R. Dubatti (Comp.), Malvinas II. La guerra en el teatro, el teatro de la guerra (pp. 7-38). Ciudad Autónoma de Buenos Aires, Argentina: Ediciones del CCC.

Dubatti, R. (2020a). Prólogo. La guerra en el teatro: representar la Guerra de Malvinas en la escena. En R. Dubatti (Comp.), La Guerra de Malvinas en el teatro argentino. Ciudad Autónoma de Buenos Aires, Argentina: Instituto Nacional del Teatro, Ediciones del CCC (en prensa).

Dubatti, R. (Comp.). (2020b). La Guerra de Malvinas en el teatro argentino. Ciudad Autónoma de Buenos Aires, Argentina: Instituto Nacional del Teatro, Ediciones del CCC (en prensa).

Eco, U. [1979] (1993). Lector in Fabula. La cooperación interpretativa en el texto narrativo. Barcelona, España: Lumen.

Dubatti, R. (5 de enero de 2020). Entrevista a Mónica Greco (Archivo de investigación de tesis doctoral). La Plata, Argentina.

Dubatti, R. (16 de marzo de 2020). Entrevista a Mónica Greco (Archivo de investigación de tesis doctoral). La Plata, Argentina.

Greco, M. y de las Heras, J. L. (1983a). "Laureles» [Texto mecanografiado inédito]. Archivo de investigación de tesis doctoral.

Greco, M. y de las Heras, J. L. (1983b). Laureles [Programa de mano]. Archivo de investigación de tesis doctoral.

Harshaw, B. (1984). Fictionality and Fields of Reference. Remarks on a Theoretical Framework [Ficcionalidad y campos de referencia. Observaciones sobre un marco teórico teatral]. Poetics Today, 5(2), 227-251.

Kon, D. (1982). Los chicos de la guerra. Hablan los soldados que estuvieron en Malvinas. Ciudad Autónoma de Buenos Aires, Argentina: Galerna.

Lorenz, F. (2007). La guerra de Malvinas y el lugar de los ex soldados en el contexto de la post dictadura (1982-1985). En S. Raggio (Coord.), Memoria en las aulas, (12), 1-29. Recuperado de http://www.comisionporlamemoria.org/archivos/educacion/memoria-enlas-aulas/dossier12.pdf 
Los "Laureles» que no pudimos conseguir. (9 de octubre de 1983). El Día, pp. 6-8.

Radice, G. y Di Sarli, N. (2008). Teatro platense en la postdictadura. La emergencia de lo político en la primera etapa de la democracia. Afuera. Estudios de crítica cultural, 3(5), 1-5.

Radice, G. y Di Sarli, N. (27 de mayo de 2009). La tendencia del Teatro Político: El Taller de Teatro Rambla [Entrada de blog]. Recuperado de http://blogteatrolaplata.blogspot. com/2009/05/la-tendencia-del-teatro-politico-el.html

Radice, G. (2020). Poética del resto y los archivos: teatro documental/documento teatral. En R. Dubatti (Comp.), La Guerra de Malvinas en el teatro argentino. Ciudad Autónoma de Buenos Aires, Argentina: Instituto Nacional del Teatro, Ediciones del CCC (en prensa).

Sigue "Laureles» en el Rambla. (11 de noviembre de 1983). El Día, s. p.

Soriano, O. (1983). Entrevista con Alain Rouquié: «Desde París, Alain Rouquié». Humor, (101), 45-50. 